\title{
PESQUISA EM FONTES PRIMÁRIAS: A OBRA ROMANESCA DE JULES VERNE, ENTRE LITERATURA E PROJETO EDITORIAL Edmar Guirra dos SANTOS
}

RESUMO: Conhecida no mundo inteiro e lida, avidamente, por um público juvenil e por um grande número de adultos, a obra de Jules Verne era menosprezada pelos acadêmicos de sua época. No século do advento da circulação de informações via impressos, o diálogo entre a literatura e a imprensa é prolífico. Ambos os campos se beneficiam dessa relação. Esse pressuposto é a base para mostrarmos como a investigação da relação escritor, editor e imprensa - no caso de Jules Verne, seu editor Pierre-Jules Hetzel e diversos jornais franceses -, nos obriga a reler as Viagens extraordinárias e a melhor compreender a localização do autor no campo literário, à margem da "grande literatura". Consideramos que parte desse desprezo poderia ser devido à participação do autor no projeto comum de Het-

${ }^{1}$ Doutorando do PPG em Letras Neolatinas (Literaturas de língua francesa) - UFRJ. Professor de língua francesa na rede Estadual do Rio de Janeiro e na Aliança Francesa-Rio. E-mail: edhalliwell2004@yahoo.com.br 
zel, o que o levou obrigatoriamente a ser classificado como escritor juvenil, não comprometido com a literariedade.

PALAVRAS-CHAVE: Jules Verne, Fonte primária, Periódicos, Campo literário.

RÉSUMÉ: Connue dans le monde entier et lue avidement par un public jeune et par grand nombre d'adultes, l'oeuvre de Jules Verne était méprisée par les académiciens de son époque. Avec l'essor de la circulation d'informations via des imprimés, le dialogue entre la littérature et la presse est prolifique. Les deux champs bénéficient de ce rapport. Ce présupposé est la base pour montrer comment l'investigation de la relation entre écrivain, éditeur et la presse dans le cas de Jules Verne, son éditeur Pierre-Jules Hetzel et plusieurs journaux français, nos oblige à relire les Voyages extraordinaires et à mieux comprendre la localisation de l'auteur dans le champ littéraire, à la marge de la « grande littérature ». On considère que ce mépris pourrait, en partie, être dû à la participation de l'auteur au projet commun de Hetzel, ce qui le conduit obligatoirement à être classé comme un écrivain pour la jeunesse qui ne s'engage pas à la littérarité.

MOTS-CLÉS : Jules Verne, Source primaire, Périodiques, Champ littéraire.

A partir das palavras proferidas por Verne em uma entrevista realizada em 1893, podemos perceber que ele nunca pôde adentrar as portas da chamada "grande literatura": "a maior decepção da minha vida é que eu nunca contei na literatura francesa” (BOIA, 2005: 11). ${ }^{2}$ Consideraremos, aqui, que as alianças entre escritor, editor e imprensa podem ser reveladoras do desdém à obra de Verne por parte da Academia.

"Leio vinte jornais por dia", confia Jules Verne, em 1904, ao jornalista Charles Dawban (COMPÈRE; MARGOT, 1998: 207). Alguns meses antes de morrer, Jules Verne se apresenta como um grande leitor de jornais e periódicos, hábito de que os especialistas não duvidam. Como poderia ser diferente para um homem que assistiu ao desenvolvimento do poder da imprensa, da qual tanto se beneficiou e que evocou na sua obra? Neste artigo, em uma reflexão sobre a "pesquisa de fontes", buscaremos demonstrar como a relação de Jules Verne com a imprensa nos obriga a efetuar uma releitura da sua obra romanesca.

Para tanto, partimos do pressuposto de que um texto é, antes de tudo, o resultado de um esforço de criação individual, dos condicionamentos sociais, das dimensões culturais, das condições econômicas, dos conflitos éticos e das contradições políticas que configuram o espaço em que foi gerado e publicado. O texto literário é constituído a partir de um mundo social e cultural que também o constitui. Pensar em uma "sociabilidade" constitutiva do texto sem recair em uma teoria do "reflexo",

${ }^{2}$ As traduções do artigo são de minha autoria. 
como propõe Dominique Maingueneau em o Discurso literário(2006), é recusar a abordagem histórica para a qual o texto é produto de seu tempo e a abordagem estilística que considera o texto como um universo fechado em si mesmo.

Jules Verne (1828-1905), autor de sessenta e quatro romances de aventura que, em conjunto, são conhecidos como Viagens extraordinárias, obteve muito sucesso com suas vendas durante o período que compreende parte do Segundo Império e a Terceira República, na França. Famosos pela edição em capa vermelha, douradura nas páginas e inúmeras ilustrações elaboradas por Georges Roux, Léon Benett, Édouard Riou e Alphonse de Neuville, destinados, sobretudo, à leitura juvenil, esses romances talvez não tivessem sido exitosos se não fossem as relações estreitas do autor com Jules Hetzel (1814-1886), seu editor, e suas ações empreendedoras no mundo da edição e no campo literário.

Muito se conhece sobre esses bem-sucedidos romances de aventura. No entanto, sabe-se muito pouco sobre a prolífera fase da carreira que antecede as Viagens extraordinárias. Já a partir de 1845, Verne escreve alguns poemas (ROBIN: 1989), aproximadamente vinte e nove textos dramáticos (BUTCHER: 2008) e uma crítica ao Salão de 1857 (Idem: 2008), tentativas malogradas de se lançar no campo literário. Somente em 1863, Jules Verne parece alcançar seu objetivo: legitimar-se como escritor. Em 1862, ele apresenta ao editor Jules Hetzel o manuscrito de um romance intitulado Voyage en l'air: une découverte de l'Afrique inconnue, survolée par un ballon manoeuvrable. Escrito como um autêntico relato de viagem, o texto leva Hetzel a pensar ter encontrado o escritor para seu futuro projeto pedagógico-editorial, o Magasin d'éducation et de récréation - revista de publicação quinzenal composta por textos didáticos agradáveis, divertidos e instrutivos. Devido ao sucesso de vendas do romance que, na verdade, será intitulado Cinco semanas num balão, um contrato é assinado e Jules Verne pôde, finalmente, começar a viver da sua literatura. Um mútuo interesse caracteriza, portanto, a associação entre escritor e editor. Esboçam-se assim as diretrizes gerais fundadoras da obra romanesca de Jules Verne, dentre as quais se destaca a utilização de fontes temáticas pinçadas dos domínios científicos e das descobertas da sua época.

Uma pesquisa mais aprofundada dos romances e suas primeiras vias de publicação revela que, com ajuda de Hetzel, Verne teve toda sua obra publicada ao longo de quarenta e um anos em formato de folhetim não só no Magasin d'éducation et de récréation, mas em diversos jornais político-literários que circulavam no meio burguês, durante parte do Segundo Império e na Terceira República, na França.

Somados, os periódicos que publicaram as Viagens extraordinárias de Verne perfazem um total de seis, sendo um magazine literário, como já citamos, e cinco jornais, a saber: além do Magasin d'éducation et de récréation, há o jornal Le Temps, Le Journal, Le Journal des débats, Le Soleil e Le Matin. O gráfico abaixo ilustra o número de romances publicados em formato de folhetim por periódico: 


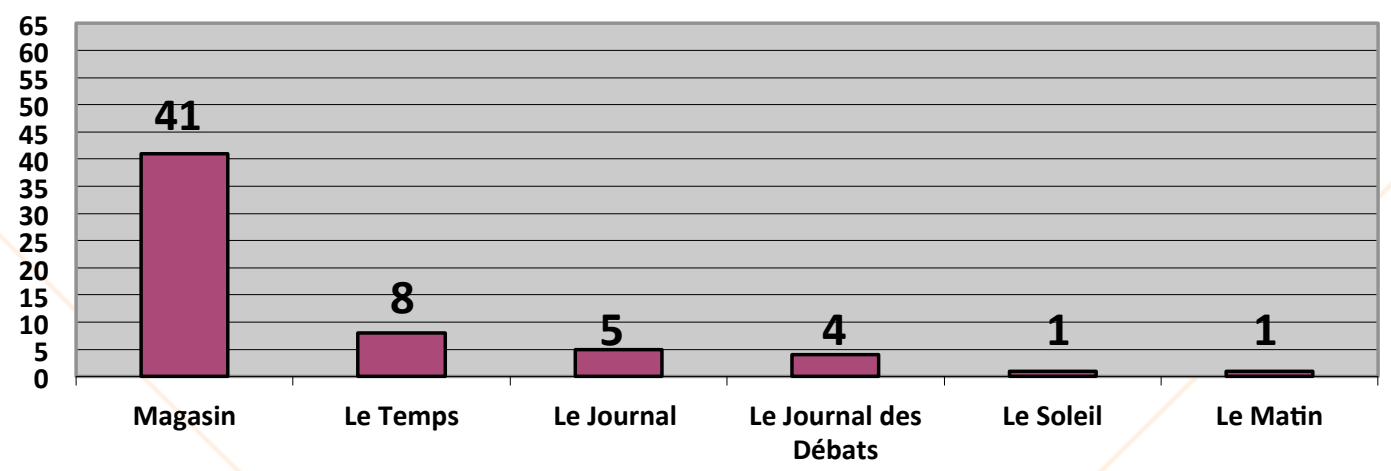

Excluiremos da discussão a relação com os periódicos Le Journal e Le Matin por tratarem da publicação de romances póstumos, cuja paternidade é frequentemente posta em questão por especialistas da obra de Jules Verne. Por traços de diferença de estilo e de tom com o restante da obra, acredita-se que Michel Verne, filho de Jules Verne, tenha terminado ou escrito tais romances. ${ }^{3}$ Um fato que reitera essa suspeita e que ultrapassa o âmbito da interpretação é que o Le Journal e o Le Matin escapam completamente da linearidade do projeto de leitura desenhado por Verne e seu editor. Essa linearidade diz respeito ao público que Hetzel e Verne objetivavam atingir: embora ambos os jornais fossem diários republicanos, eram destinados à leitura popular enquanto os outros quotidianos em que Verne publicou se alimentavam das vendas para um público burguês (CHARLES, 2004: 160). Isso leva a crer que o filho de Jules Verne, detentor dos direitos da obra depois de sua morte, já realizava outras alianças no mundo da edição, diferentes daquelas efetuadas pelo pai e seu editor.

A relação com esses periódicos, diversos no que tange ao público alvo, aos objetivos e às tendências políticas, nos conduz a uma primeira questão: por que publicar em jornais ou magazines literários? Essa seria uma pergunta de resposta evidente se Verne tivesse utilizado desses meios somente para divulgar seu nome, o que acontece com frequência no início da carreira de alguns escritores. Mas não o é. Verne publica seus romances em formato folhetim até 1905, ano de sua morte, transpondo até mesmo a morte de seu editor, em 1886, aquele responsável por estabelecer as alianças com os diários.

Reconhecer a importância de Jules Hetzel na carreira de Jules Verne é imperativo. Não fosse o editor e suas frequentes coerções, talvez o nome de Verne não tivesse despontado no campo literário francês. ${ }^{4}$ No entanto, muito se lê sobre a incompetência administrativa de Hetzel (CHARTIER; MARTIN, 1990: 210-211). Até o ano de 1863, data da publicação de Cinco semanas num balão, primeiro ro-

3 Tal suspeita, levantada por Piero Gondolo dela Riva em 1978, é retomada na biografia de Jules Verne, escrita por William Butcher. Veja: BUTCHER, 2006: 297-298.

4 Compreende-se por Campo literário, conceito proposto pelo sociólogo Pierre Bourdieu, um espaço simbólico, no qual as lutas dos agentes determinam, validam e legitimam representações. Nele se estabelece uma classificação dos signos, do que é adequado, do que pertence ou não a um código de valores (BOURDIEU, 1990: 149-168). 
mance verniano, Jules Hetzel colecionou inúmeros fracassos editoriais e ruínas financeiras. Ora, se o autor das Viagens extraordinárias precisou do editor para fazer um nome no campo literário, Hetzel precisou de Verne para manter erguida sua editora, obtendo altos lucros com a vendagem dos folhetins. Charles-Noël Martin calcula que os ganhos de Jules Verne com sua obra não ultrapassam um milhão de francos, enquanto renderam trinta milhões a Hetzel (Idem: 213).

A partir desses dados, conjecturamos que Jules Hetzel estabelecia relação com diários porque precisava manter o poder da sua editora no campo literário ao longo do Segundo Império e parte da Terceira República. Junto a jornais de grande circulação, o editor podia reforçar e estabelecer novas alianças mantendo em evidência o nome de sua editora, usando, para isso, as cifras que o nome de Jules Verne lhe rendia. A associação entre editor e escritor poderia se caracterizar como uma relação de simbiose, mutuamente vantajosa. Essa relação se inicia ainda em 1864. Nesta época, os objetivos de Hetzel não se restringiam somente em publicar Cinco semanas num balão. O editor tinha o desejo de criar "uma biblioteca associando educação e recreação" (COMPÈRE, 1996: 15).

Impulsionado pelas ideias políticas do Segundo Império que iam em direção a uma publicação especializada de tendência "não política", já que a administração imperial era severa com os jornais que incluíam esse tipo de discussão ou economia social em suas páginas (KALIFA et alii, 2011: 236), Hetzel une-se a Jean Macé, em março de 1864, para a criação do Magasin d'éducation et de récréation, que seria a vitrine da sua editora. O primeiro preocupava-se em defender uma moral laica e a ideologia republicana; o segundo, em fornecer informações técnicas e científicas à juventude. As linhas do editorial da revista são esclarecedoras a esse respeito:

Ao iniciar a publicação desta Revista de Educação e de Recreação, temos a consciência de empreender uma obra difícil, e se não recuamos diante da dificuldade da empresa é porque temos consciência da sua grande utilidade. Trata-se, para nós, de constituir um ensino de família no verdadeiro sentido da palavra, um ensino sério e atraente ao mesmo tempo, que agrade aos pais e seja proveitoso para as crianças. Educação, recreação são, em nossa opinião, dois termos convergentes. O instrutivo deve se apresentar de um jeito que provoque o interesse: sem isso ele repele e cansa; a diversão deve conter uma realidade moral, ou seja, útil: sem isso ela se torna fútil e esvazia as cabeças ao invés de enchê-las. Nisso deverá residir a unidade da nossa obra, que poderá, se obtiver sucesso, contribuir para o aumento da massa de conhecimentos e de ideias sadias, de bons sentimentos, de inteligência, de razão e de gosto que forma o que poderíamos chamar de capital moral da juventude intelectual da França. Acrescentar à lição forço- 
samente um pouco austera do colégio e do pensionato uma lição mais íntima e mais penetrante, completar a educação pública pela leitura no seio familiar, tornar-nos os amigos da casa em todos os lugares que pudermos entrar, agir ao mesmo tempo em todos os elementos de que ela se compõe, responder a todas as necessidades de aprender que se desenvolvem no lar, desde o berço até a maturidade, tal é nossa ambição (MACÉ; STHAL, 1864: 1).

Seguindo esses objetivos, Verne se associa ao projeto lúdico-instrutivo da editora de Hetzel a quem precisa submeter três volumes por ano, como rezava no seu contrato, em 1865.Com assinatura a 12 francos ao ano ou 50 centavos o exemplar (KALIFA et alii, 2011: 394,514), a revista segue o modelo dos "magasin" da Monarquia de julho, cujo sucesso se deveu às páginas ilustradas e ao formato de paginação contínua podendo, ao final de um período, ser publicada em volume (Idem; 391).

Como mostramos no gráfico acima, com a intenção de completar o ensino público e formar o capital moral e intelectual da juventude francesa, Verne publicou quarenta e um de seus romances em formato de folhetim, nesse periódico, ou seja,65\% da sua obra seguiram os objetivos ditados no editorial que, em parte, citamos. Trata-se para nós de refletir sobre a relação entre a obra romanesca de Verne e revista ou os jornais, ateliês primários e lugares de compreensão das mutações poéticas da literatura no século XIX, como sublinha Marie-Ėve Thérenty em seu livro La Littérature au quotidien: poétiques journalistiques au XIX siècle (2007: 17-18). A autora explica que o contrato de leitura implícito imposto pela estrutura de uma publicação em volume difere das condições de leitura de um periódico. Assim, um mesmo texto, pelo simples fato da mudança de suporte, pode tomar sentidos diferentes. Portanto, a porcentagem citada, além de endossar o vínculo da obra verniana ao gênero da literatura juvenil, ditará o ritmo da escrita de Verne: a periodicidade quinzenal da revista terá efeitos na poética do escritor. Para a criação das suas histórias, implicado em uma produção seriada, Verne deverá levar em conta as condições de leitura ligadas ao suporte: os intervalos regulares na leitura acarretam efeitos positivos como o da "espera ansiosa do próximo capítulo" e, portanto, de fidelização do leitor.

Segundo Kalifa et alii (2011: 1515), o fenômeno da publicação seriada pode se dar em escalas variadas. Em uma pequena escala, explicará a recorrência de sequências narrativas similares em um folhetim (peripécia/problema- desenvolvimento - solução do problema). Essa fórmula é particularmente cara a Jules Verne, pois, nesse molde, a independência das histórias e dos episódios dentro da história também são priorizados; eles têm efetivamente um fim, não são cíclicos. Com essa fórmula, se aceita o princípio de descontinuidade diegética, o que permitirá destacar de cada folhetim do jornal, sua leitura seriada, sua reunião em brochura antes de sua posterior publicação em volume. Queremos dizer que a fórmula 
romanesca verniana é multifuncional: permite ao autor publicar em folhetim e posteriormente em volume, realizando a longo prazo o projeto maior da série Viagens extraordinárias, o que o leva, assim, a diferentes momentos de sua produção, revisão e também à possibilidade de atingir diversos públicos.

Para nós, é bastante claro que o reconhecimento da pesquisa de fonte sem periódicos, efetuada por Verne dentro do projeto Verne-Hetzel para a escrita de seus romances, auxilia na compreensão das escolhas estilísticas do autor e de determinados rumos que sua carreira tomou. Afinal, foi pela e para a imprensa que as ficções que compõem a série de Viagens extraordinárias foram concebidas. Por exemplo, a compreensão da sua "escolha" genérica e sua vocação instrutiva não deve estar dissociada de uma pesquisa atenta do Magasin d'éducation et de récréation da editora de Hetzel. No entanto, a prolífica publicação nos rodapés de jornais também não deve ser negligenciada. A salianças do editor com os diários $L e$ Temps e Le Journaldes Débats enriquecem a discussão.

Em termos biológicos, a protocooperação é uma relação benéfica para ambas as espécies envolvidas, embora não lhes seja indispensável. Os seres associados mantêm certa independência: apenas se beneficiam das associações mais ou menos duradouras que estabelecem. Se considerando o número menor de colaborações de Verne comparadas àquelas do Magasin d'éducation et de récréation, o termo científico - usado aqui metaforicamente - é próprio para ilustrar as relações efêmeras, ainda que importantes, entre Verne, Hetzel e os jornais citados.

Graças a Hetzel e seu empreendedorismo no mundo da edição e no campo literário, a associação com esses diários foi possível. No Journal des Débats, jornal burguês de tendência centro-direita (CHARLE, 2004: 160) no Segundo Império, Jules Verne publicou quatro romances-folhetim: Da Terra à lua (1865), Viagem ao redor da lua (1869), Uma cidade flutuante (1871) e Robur, o conquistador (1886). Sob a direção de Édouard Bertin, o jornal "político e literário" se distinguia do Le Temps por destinar três páginas à literatura folhetinesca, enquanto seu maior concorrente utilizava somente duas. O diário Le Temps, fundado por Auguste Nefftzer em abril de 1861, era igualmente destinado a um público burguês, mas mantinha a tendência centro-esquerda na política (Idem). O diário traz no editorial da primeira edição a repetição da palavra "Liberdade" que acreditava estar vinculada à educação política das massas. ${ }^{5}$ Por creditar ao ensino público e à imprensa a difusão de conhecimento, Nefftzer encontrou na associação com o Magasin de Hetzel, de fevereiro de 1864 a fevereiro de 1865, a possibilidade de expansão do seu público leitor e, com a fidelização, maior estabilidade nas vendas. O anúncio da revista como «brinde » aos assinantes é publicado em 29 de fevereiro de 1864, ocupando a primeira e a segunda colunas da primeira página do jornal:

$5 \mathrm{O}$ editorial completo está disponível em: http://gallica.bnf.fr/ark:/12148/bpt6k220905j.langFR. Último acesso em: 08/05/2014. 
Ela [a revista] será endereçada, quinzenalmente, a título de anexo gratuito, a todos os novos assinantes do Temps. [...] É inútil acrescentar que os nomes dos diretores e do editor garantem a moralidade e o espírito que animam a Revista de educação e de recreação. Em acordo conosco há algum tempo, não haverá entre sua obra e a nossa nenhuma dissonância. Nós a associamos ao Temps, como um complemento legítimo há algum tempo desejado. ${ }^{6}$

Um dia depois, um espaço na primeira página do jornal é igualmente destinado aos editores da revista para anunciar o programa do Magasin. O mesmo programa que consta do editorial que já citamos.

Essa associação rendeu ao Magasin d'éducation et de récréationa possibilidade de divulgar o nome do novo projeto da editora de Hetzel. Em 1875, a revista atinge dez mil assinantes (CHARTIER; MARTIN, 1990: 212). Ao total, autor, editor e diretor do jornal, ainda tiraram proveito da vendagem de oito romances-folhetim de Jules Verne: A volta ao mundo em 80 dias (1873), O Chancellor (1874), As Índias negras(1877), As tribulações de um chinês na China(1879), $O$ raio verde (1882), $O$ arquipélago em chamas(1884), Mathias Sandorf (1885) e O caminho da França (1887).

Trata-se para nós de questionarmos, igualmente, sobre as relações harmônicas ou desarmônicas das notícias que emolduram os folhetins. O caso da famosa aventura A Volta ao mundo em 80 dias pode ser exemplar. Publicada em formato folhetim entre novembro de 1872 e final de janeiro de 1873, no diário Le Temps, o romance dividia as páginas com notícias da atualidade internacional. O capítulo inaugural do folhetim7 é alocado em uma página onde se lê "Les Dépêches Télégraphiques du Monde": suas colunas trazem subtítulos com nomes de diversos países e cidades em forma de notícias rápidas. Aqui, a pesquisa de fontes nos revela que a vocação instrutiva de Jules Verne tem sentido na economia geral de uma revista ou, nesse caso, de um jornal com os efeitos de eco sendo trabalhados entre o romance-folhetim e os artigos que o circundam.

Graças à pesquisa nos periódicos, a questão que diz respeito às notícias que concorrem espaço com o folhetim pode se estender: em que medida as informações paratextuais do jornal ou da revista se relacionam com as opções estéticas do escritor? Embora não tenhamos uma resposta definitiva à questão, podemos dizer hipoteticamente que retirar essas ficções das revistas ou jornais onde foram publicadas poderia minimizar a função da "viagem instrutiva" do romance, modificando sua leitura e fugindo dos objetivos primeiros do jornal, do editor e do escritor.

A relação entre o formato folhetinesco e a interferência na poética do escritor também pode ser exemplificada aqui. O romance-folhetim As Índias negras, que

${ }^{6}$ Este anúncio pode ser lido na íntegra em: http://gallica.bnf.fr/ark:/12148/bpt6k221948b.zoom. Último acesso em: 08/05/2014.

7 A página do folhetim está disponível em: http://gallica.bnf.fr/ark:/12148/bpt6k225186k.langFR. Último acesso em: 08/05/2014. 
apareceu entre 28 de março de 1877 e 22 de abril do mesmo ano, nas páginas do jornal Le Temps traz, em suas "quebras de capítulo", finais que, normalmente, despertam a curiosidade do leitor para comprar o próximo número do jornal e ler o próximo capítulo, sobretudo, após a menção de um "tentador" à suivre ou suite à demain. Assim, ao final da primeira parte desse romance que trata do paralelismo entre a riqueza das Índias orientais com a riqueza gerada pela Revolução Industrial no ocidente e impulsionada pelo carvão, o personagem James Starr - escocês, antigo diretor de uma usina de carvão -, recebe uma carta misteriosa, sem assinatura e de frase única: "Inútil ao Sr. Starr de se incomodar". A carta além de lançar a trama, servirá para atrair a curiosidade do leitor e, ainda, como "gancho" para iniciar o capítulo do dia seguinte: "O fluxo de ideias de James Starr foi bruscamente interrompido quando recebeu essa carta [...]"9. Assim, Jules Verne, para se adequar ao formato folhetim dentro do suporte jornal, tem de dar conta de coerções como o tamanho do capítulo - aqui somente um "rodapé de página" -, ou o fechamento do mesmo, que interferem obrigatoriamente na sua poética. Como sinaliza Marie-Ėve Thérenty (2007: 47), a periodicidade do jornal faz com que o escritor se assemelhe mais a um profissional assalariado, forçado a entregar uma produção regular, do que a um artista inspirado, portanto, menos preocupado com a literariedade, algo que, no caso de Jules Verne, contribuiria para distanciá-lo das portas da "grande literatura".

Há ainda outras questões que não priorizamos aqui, mas podem ser levantadas. Por exemplo, no que tange ao número de volumes vendidos, qual é a interferência da (pré)divulgação das narrativas em formato folhetim? Em que medida o sucesso de vendagem está atrelado a esse tipo de publicação? Como Dumas ou Sue, Jules Verne alcança notoriedade "popular"?

Em hipótese, afirmamos que o suporte jornal e o formato folhetinesco servirão de ateliê primário e vitrine para a parte mais conhecida da obra de Jules Verne, as Viagens extraordinárias. O resultado das alianças entre escritor, editore os diversos jornais ou periódico auxiliará na difusão do nome de Jules Verne e de sua obra, e na posterior vendagem dos volumes tornando o escritor "conhecido" de um público maior, no entanto burguês, mas não "reconhecido" pela "grande literatura". Acreditamos que as respostas definitivas a essas questões poderão auxiliar em um maior detalhamento das informações sobre a "escolha" do gênero para o qual Jules Verne escreve, investigando em que medida o investimento na literatura difundida inicialmente em páginas de jornais ou periódicos se relaciona à condição tópica do autor no campo literário.

\footnotetext{
${ }^{8}$ A página a que nos referimos está disponível em: http://gallica.bnf.fr/ark:/12148/bpt6k2268560.image.langFR. Último acesso em 08/05/2014.

9A página está disponível em: http://gallica.bnf.fr/ark:/12148/bpt6k226857c.image.langFR. Último acesso em: 08/05/2014.
} 
BOIA, Lucien. Jules Verne: les paradoxes d'un mythe.Paris: Les Belles lettres, 2005.

BOURDIEU, Pierre. Coisas ditas. Trad. Cássia Silveira \& Denise Pegorim. São Paulo: Brasiliense, 1990. B

BUTCHER, William. Jules Verne. The definitive biography. New York: Thunder's Mouth Press, 2006. . Salon de 1857 - Jules Verne. [S.L.]: Acadien, 2008.

CHARLE, Christophe. Le siècle de la presse. Paris: Seuil, 2004.

CHARTIER, Roger \& MARTIN, Henri-Jean. Histoire de l'édition française: le temps des éditeurs. Paris: Fayard, 1990 (1985).

COMPÈRE, Daniel. Jules Verne. Parcours d'une oeuvre. Amiens: Encrage, 1996.

COMPÈRE, Daniel \& MARGOT, Jean-Michel. Entretiens avec Jules Verne. Genève: Slatkine, 1998.

KALIFA, Dominique; RÉGNIER, Philippe; THÉRENTY, Marie-Ève \& VAILLANT, Alain (dir.). La civilisation du journal: histoire culturelle et littéraire de la presse française au XIX ${ }^{\mathrm{e}}$ siècle. Paris: Nouveau monde, 2011.

MACÉ, Jean \& STHAL, P.-J. Magasin d'éducation et de récréation, Paris: Hetzel, Mar/1864. http://gallica.bnf.fr/. Último acesso em: 08/05/2014.

MAINGUENEAU, Dominique. Discurso literário. (Trad. Adail Sobral). São Paulo: Contexto, 2006.

ROBIN, Christian. Jules Verne: poésies inédites. Paris: Le Cherche midi, 1989. Théâtre inédit. Paris: Le Cherche midi, 2005.

THÉRENTY, Marie-Ève. La Littérature au quotidien: poétiques journalistiques au XIX siècle.Paris: Seuil, 2007. 